\title{
Influence of Moisture Content on Mechanical Properties of Autoclaved Aerated Concrete
}

\author{
Chunning Deng, Weiqun Cai, Jian Yin*, Fen Yang, Linchen Li \\ College of Civil Engineering, Central South University of Forestry and Technology, Changsha, China \\ Email address: \\ 1002919857@qq.com (Jian Yin) \\ ${ }^{*}$ Corresponding author
}

To cite this article:

Chunning Deng, Weiqun Cai, Jian Yin, Fen Yang, Linchen Li. Influence of Moisture Content on Mechanical Properties of Autoclaved Aerated Concrete. International Journal of Transportation Engineering and Technology. Vol. 5, No. 4, 2019, pp. 97-102.

doi: 10.11648/j.ijtet.20190504.16

Received: November 20, 2019; Accepted: December 16, 2019; Published: December 24, 2019

\begin{abstract}
Autoclaved aerated concrete (AAC) is a new type of green building material rapidly developed nowadays. Moisture content plays a significant effect on its mechanical properties. In this study, a series of uniaxial compression tests were conducted to evaluate the effect of moisture content on the mechanical behaviors. During the tests, full stress-strain curves were obtained. The influence of water content on AAC stress-strain full curve shape, elastic modulus, peak stress, peak strain and ultimate strain was analyzed. The fitting equations of water content with peak stress, peak strain and elastic modulus were established. The results show that the brittleness of AAC decreased with the increased of water content, and the failure mode gradually transited from brittle to ductile failure. When the water content increased from $0 \%$ to $10 \%$, obvious difference in the stress-strain curves can be observed. The peak stress decreased by $20.00 \%$ and $11.63 \%$ when the moisture content was $5 \%$ and $10 \%$, respectively. However, when the water content increased from $10 \%$ to $40 \%$, the peak stress decreased slowly. The rising section relation model of AAC stress-strain full curve can be fitted by cubic polynomial, which provided reference basis for finite element analysis.
\end{abstract}

Keywords: Autoclaved Aerated Concrete (AAC), Moisture Content, Uniaxial Loading, Peak Strain, Stress-strain Curve

\section{Introduction}

Autoclaved aerated concrete (AAC) is a new type of green building material vigorously developed in our country. ACC is of light weight, heat insulation, sound insulation, sound absorption, earthquake resistance, fire prevention and other advantages. However, in most building structures, ACC is basically used as the wall filler or roof thermal insulation materials, and generally used for non-bearing structures [12]. If it is used in a load-bearing structural system, its good physical properties and load-bearing capacity can be combined into one. However, due to the randomness of pore structure changes in ACC, under the action of water, the effect of water molecules on solid molecules and the degree of filling in pores are different, resulting in changes in its microstructure, thus affecting its mechanical properties. Therefore, it is very necessary to explore the mechanical properties of AAC under different moisture contents [3].
In terms of uniaxial compression mechanical properties, Zeng studied the stress-strain complete curve equation of autoclaved fly ash-sand aerated concrete prism under uniaxial stress, and analyzed its failure form and geometric characteristics of the curve [4]. Zhang and Chen studied the relationship between the axial compressive strength and the cube compressive strength, the relationship between loading direction and compressive strength, size effect and the relationship between splitting tensile strength and compressive strength of aerated concrete through basic mechanical performance tests [5]. D ferretti studied the mechanical properties of AAC masonry under uniaxial and biaxial loads through experimental research and nonlinear finite element simulation [6]. A. Bonakdar measured the relationship between stress and axial strain, the relationship between stress and lateral strain of autoclaved aerated concrete and fiber reinforced aerated concrete respectively through compression tests, and calculated the elastic modulus and Poisson's ratio by using curves [7]. On the influence of 
water on $\mathrm{AAC}, \mathrm{Yu}$ obtained the mathematical relationship between the measured compressive strength with different water contents and the reference compressive strength of AAC with water contents of $8 \% \sim 12 \%$ through a combination of a large number of experimental studies and regression analysis [8]. Zbayek Pavlí k studied the calibration of high frequency time domain reflectometry (TDR) for measuring water content of porous building materials and the effect of water content on the behavior and performance (thermal, acoustic and mechanical properties) of porous buildings [9]. R Drochytka focused on the heat and moisture properties of various porous concrete materials with densities between 300 and $400 \mathrm{~kg} / \mathrm{m} 3$ and the influence of a certain amount of water on the mechanical properties and durability of porous building materials [10].

In conclusion, the research on the influence of water content on AAC's mechanical properties mainly focuses on mechanical properties such as strength. However, the research on AAC's constitutive relation under different water content is limited, which is not conducive to the calculation and analysis of structures. Therefore, it is of great significance to study the mechanical properties of AAC under different water content conditions to improve the structural calculation and analysis of AAC in the structural system.

\section{Test}

\subsection{Raw Materials}

The test selected AAC block with the strength grade A3.5 and size of $600 \mathrm{~mm} \times 200 \mathrm{~mm} \times 200 \mathrm{~mm}$. The specimen preparation was carried out according to GB/T 11969-2008 "Autoclaved Aerated Concrete Performance Test Method". The main performance indexes were showed in Table 1.

Table 1. AAC Performance Parameters.

\begin{tabular}{llll}
\hline Model & Bulk density $/ \mathbf{k g} / \mathbf{m}^{3}$ & $\begin{array}{l}\text { The average intensity } \\
\text { of/MPa }\end{array}$ & Size/mm \\
\hline A3.5 B06 & 588 & 4.0 & $100 \times 100 \times 100$ \\
\hline
\end{tabular}

\subsection{Moisture Content Control Process}

According to GB/T 11969-2008, the test specimens absorbed water first and then put into an electric air-blast drying box. The temperature was controlled within the range of $65 \pm 5^{\circ} \mathrm{C}$. The test piece was baked to the required moisture content $(0 \%, 5 \%, 10 \%, 20 \%, 30 \%, 40 \%, 50 \%, 60 \%)$, and then was vacuumized and sealed with a vacuum bag and put into a closed container for 72 hours, so that the moisture content can be evenly distributed in the specimens [8].

\subsection{Test Plan}

An ANSCMT 5105 micro-computer controlled electronic universal testing machine was used for loading. The loading system mainly consists of compression test device, moving beam and controller.

Uniaxial compression tests were conducted on six samples with different moisture content. Loading procedures include two parts. Before the pressure value of the force sensor reaches $60 \% \sim 70 \%$ of the predicted bearing capacity of AAC, the samples were compressed stress-controlled with a loading rate of $2000 \mathrm{~N} / \mathrm{s}$. When the applied load exceeds $70 \%$ of the predicted peak value of concrete, the testing machine program controls loading at a rate of $0.6 \mathrm{~mm} / \mathrm{min}$. All the test pieces were loaded to the residual strength stage, and the force-displacement curve and its corresponding displacement value and pressure value were obtained by using the microcontrol system program of the testing machine [11].

\section{Test Results}

\subsection{Failure Characteristics}

Uniaxial compression test was carried out on AAC cube with different moisture content. During the loading process, it can be clearly observed that there was no obvious visible crack on the surface of AAC specimen before the maximum stress was obtained. At this time, the deformation of specimen mainly included the development of microcracks and volume compression. When the stress reached the maximum value, a main crack started to appear on the surface of the specimen, and it expanded rapidly until it was destroyed, which was a brittle failure feature. The failure modes of AAC specimens mainly include splitting failure, oblique section shear failure, "splayed" failure and corner failure [5]. The test results show that when the moisture content of AAC cube specimen was less than $10 \%$, the specimen was destroyed suddenly, accompanied by a large splitting noise, and the crack stopped propagating after the destruction. The failure mode was to form a vertical microcrack from the top or bottom of the specimen. With the increase of load, the crack expanded continuously to form a wider crack until the specimen was destroyed. The failure mode of the specimen was split as shown in Figure $1 \mathrm{a}$ and $\mathrm{b}$. However, when the water content of AAC specimens was greater than $10 \%$, there was no splitting sound when the specimens were destroyed, and the destruction process was relatively slow. With the increase of water content, the destruction form of AAC specimens changed from brittleness to ductility, because the AAC strength at this time was reduced, the internal voids were filled with lots of free water, the friction force and chemical bonding force between aggregate particles and cement hydration products decreased, and the bearing capacity also decreased. The failure feature showed that microcracks first formed from the top or bottom of the specimen. However, with the increase of load, the cracks gradually extended and expanded, eventually forming oblique cracks running through from top to bottom. As shown in Figure $1 \mathrm{c}$ and $\mathrm{d}$, the failure of the specimen was "splayed" or corner failure.

Compared with the damage style of ordinary concrete, AAC's damage form had no obvious " $\mathrm{X}$ " marks. This is because the forming process and pore structure of autoclaved aerated concrete are different from those of ordinary concrete. Aluminum powder released hydrogen through 
chemical reaction to generated pores. The gas generation conditions were harsh, the pore structure was poor, the pore size was wide, and there were many large pores, extra-large pores and connecting pores, which increased the probability of defects such as pores, cracks and poor local bearing capacity existing in AAC. For brittle materials, these were prone to stress concentration, so the failure process of

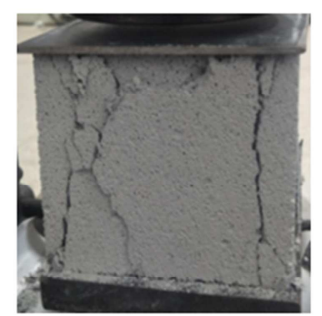

(a) water content $5 \%$

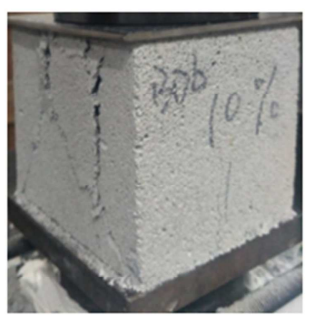

(b) water content $10 \%$

specimens was short [12-13]. In addition, a large number of pores with different pore diameters were distributed on the surface of AAC specimens, which weakened the friction force between the specimen surface and the bearing plate of the testing machine and reduced the "hoop effect" of the specimen end face. Therefore, the failure mode of AAC cube specimens was mainly split failure or "splayed" failure.

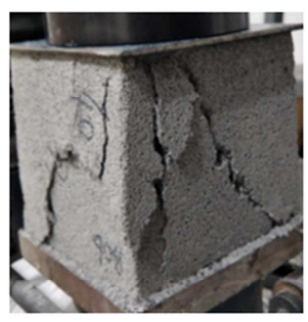

(c) water content $40 \%$

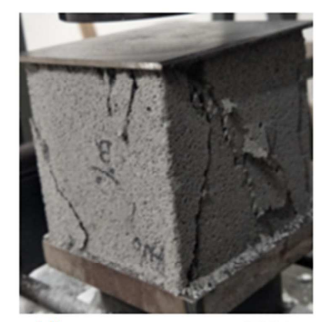

(d) water content $50 \%$

Figure 1. Uniaxial compression failure modes of AAC with different moisture.

\subsection{Influence of Water Content on AAC Peak Stress and Peak Strain}

Figure 2 presented the stress-strain curves of specimens with different water content. Table 2 showed some basic mechanical parameters, including peak stress, peak strain, elastic modulus and residual strength under different water content. Test results in Figure 2 showed that the water content played a significant impact on the AAC stress-strain curve. With the increase of water content, the peak stress of AAC gradually decreased. When the water content was greater than $10 \%$, each AAC specimen presented an obvious plastic compression process at the peak load stage, indicating that the strength of AAC decreased, the bearing capacity decreased, the failure form changed from brittleness to certain ductility, and the brittle failure of AAC was delayed.

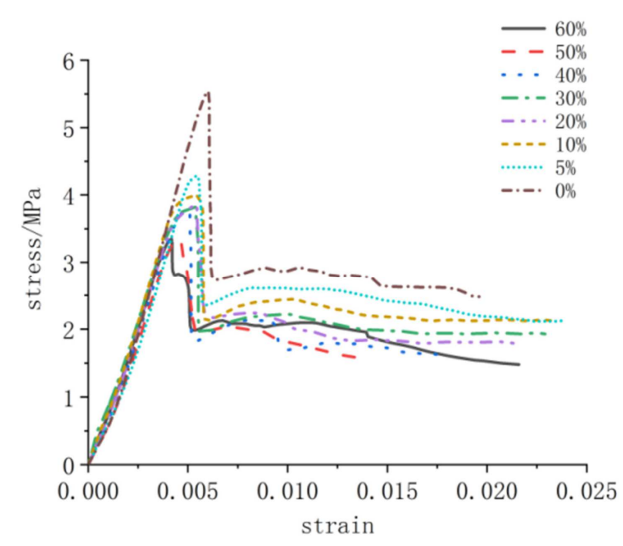

Figure 2. The full cureve of uniaxial compressive stress-strain of AAC.

Table 2. Basic mechanical properties of AAC.

\begin{tabular}{|c|c|c|c|c|c|}
\hline $\begin{array}{l}\text { The moisture content } \\
/ \%\end{array}$ & $\begin{array}{l}\text { Peak stress } \\
/ \mathrm{MPa}\end{array}$ & $\begin{array}{l}\text { Peak strain } \\
/ 10^{-3}\end{array}$ & $\begin{array}{l}\text { Modulus of elasticity } \\
\text { /MPa }\end{array}$ & $\begin{array}{l}\text { Residual strength } \\
/ \mathrm{MPa}\end{array}$ & $\begin{array}{l}\text { Residual strength/peak stress } \\
/ \%\end{array}$ \\
\hline 0 & 5.59 & 6.08 & 1133.6 & 2.64 & 47.2 \\
\hline 5 & 4.47 & 5.57 & 1021.8 & 2.42 & 54.1 \\
\hline 10 & 3.95 & 5.56 & 973.9 & 2.18 & 55.2 \\
\hline 20 & 3.88 & 5.39 & 954.4 & 1.83 & 47.2 \\
\hline 30 & 3.82 & 5.34 & 943.5 & 1.98 & 51.8 \\
\hline 40 & 3.79 & 5.22 & 939.1 & 1.73 & 51.8 \\
\hline 60 & 3.35 & 4.27 & 909.7 & 1.82 & 54.3 \\
\hline
\end{tabular}

Note: The elastic modulus is $0.3 \sim 0.8$ times of the peak stress in the rising section of the stress-strain curve and can be obtained by calculating the slope; When the strain value is 0.015 , the corresponding stress is residual strength [14].

The relationship between peak stress, peak strain and water content in AAC stress-strain curve was shown in Figure 3 and Figure 4. From Table 2 and Figure 3, it can be seen that the peak stress of AAC gradually decreased with the increase of water content, but the reduction amplitude of peak stress corresponding to adjacent water content was different. When the water content was $0 \%$, the average peak stress of the test piece was $5.59 \mathrm{MPa}$. When the water content was $5 \%, 10 \%, 20 \%, 30 \%, 40 \%, 50 \%, 60 \%$, the average peak stress of the corresponding test piece was $4.47 \mathrm{MPa}$,
3.95MPa, 3.88MPa, 3.82MPa, 3.79MPa, 3.34MPa, 3.35MPa. Compared with the specimens with a one steps lower water content, the amplitude of peak stress decreased successively was $20.00 \%, 11.63 \%, 1.77 \%, 1.55 \%, 0.78 \%, 11.87 \%$ and $0.30 \%$ respectively. It can be seen that when the water content was from $0 \%$ to $10 \%$, the peak stress decreased sharply with the increase of water content. From 10\% to $40 \%$, the peak stress decreased slowly, which was similar to the test results in reference [15]. The reason for this was that the intrusion of water molecules weakened the connection of 
particles inside the material, and when the intrusion of water molecules reached a certain degree, the main factor affecting the strength and deformation performance of the material became the material composition and structure inside the material itself [16]. Through fitting analysis, the relationship between AAC water content and its peak stress under different water content conditions was as follows:

$$
f_{\text {aac }}=-0.83535 \omega^{0.23644}+5.58944 \quad\left(R^{2}=0.95392, n=8\right)
$$

Where: faac is the peak stress of $\mathrm{AAC}, \mathrm{MPa} ; \omega$ is water content, $\% ; \mathrm{R}$ is the fitting coefficient.

As can be seen from Table 2 and Figure 4, the peak strain of AAC gradually decreased with the increase of water content. From $0 \%$ to $60 \%$, the peak strain of AAC decreased by $27.5 \%$. Through fitting analysis, the relationship between AAC water content and peak strain under different water content conditions was as follows:

$$
\varepsilon_{\text {aac }}=-1.9764 \times 10^{-5} \omega^{3}+0.00156 \omega^{2}-0.05212 \omega+6.45882\left(R^{2}=0.95275, n=8\right)
$$

Where: $\varepsilon_{\text {aac }}$ is peak strain of AAC.

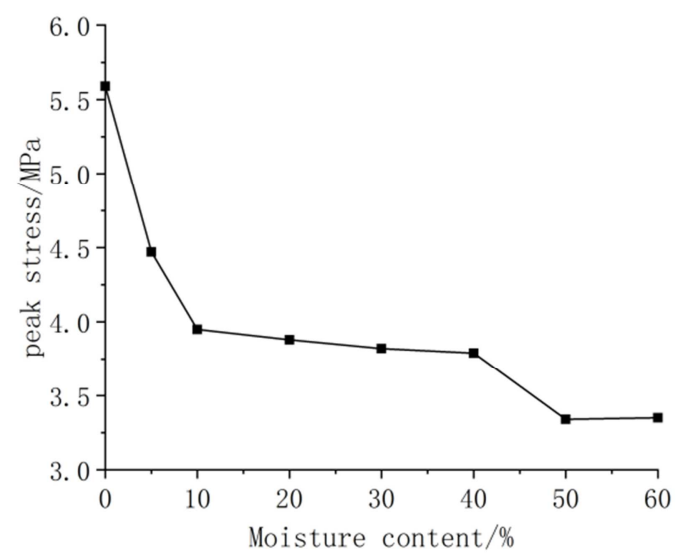

Figure 3. Contact between water content and peak stress.

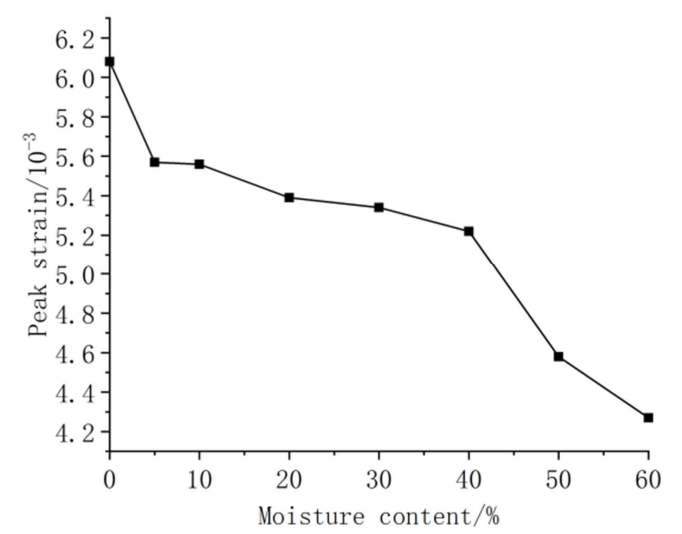

Figure 4. Contact between water content and peak strain.

\subsection{Influence of Moisture Content on AAC Elastic Modulus}

Figure 5 showed the relationship between water content and AAC elastic modulus in AAC stress-strain curves. From Table 2 and Figure 5, it can be seen that the influence of water content on AAC elastic modulus was similar to the influence law on compressive strength. The relation between AAC elastic modulus and water content under different water content conditions was as follows:

$$
E_{\text {aac }}=-84.1257 \omega^{0.24267}+1134.04998\left(R^{2}=0.9802, n=8\right)
$$

Where: Eaac is the elastic modulus of AAC, MPa.

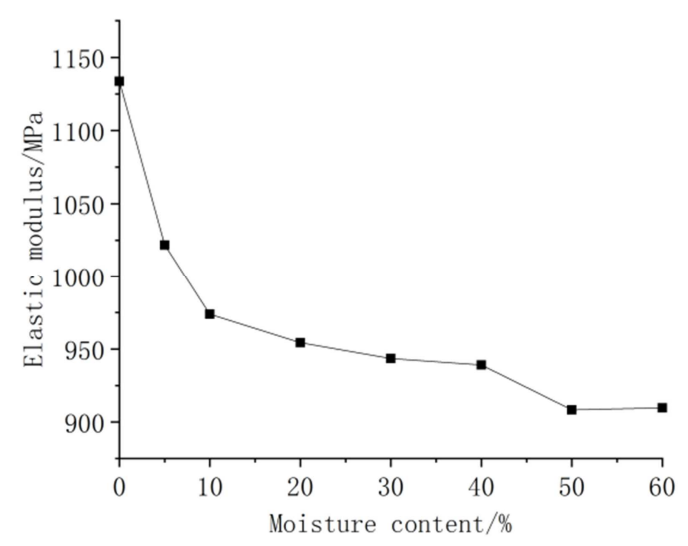

Figure 5. Relationship between moisture content and elastic modulus.

\subsection{Constitutive Relationship of AAC under Different Moisture Content Conditions}

After standardizing the measured data of AAC stress-strain curves under different water content conditions (The abscissa is the corresponding strain value divided by peak strain, the ordinate is the corresponding stress value divided by peak stress $\left.\left(x=\varepsilon / \varepsilon_{a a c}, \quad y=\sigma / f_{a a c}\right)\right)$, the obtained dimensionless uniaxial compressive stress-strain curve was shown in Figure. 6 , where $\sigma$ is stress, $\varepsilon$ is strain.

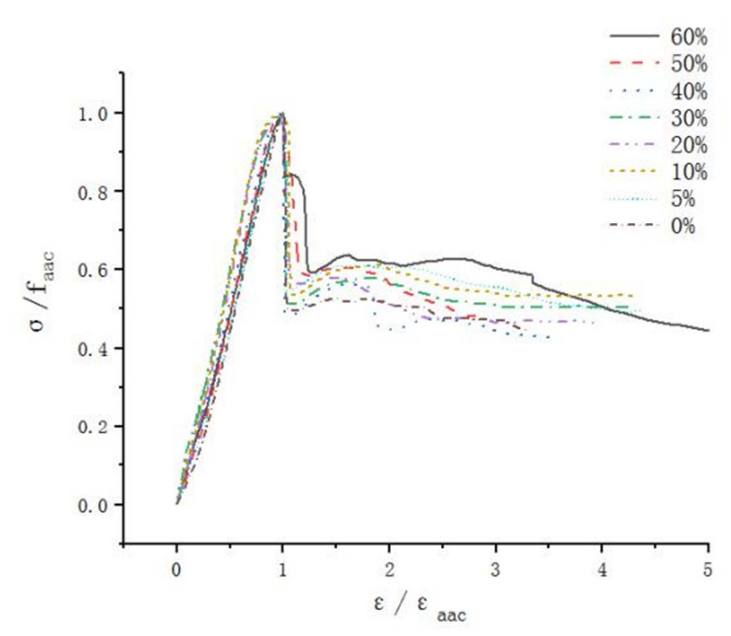

Figure 6. Dimensionless stress-strain curve of $A A C$.

Based on the constitutive equation of aerated concrete recommended by Professor Guo Zhenhai [17] of Tsinghua 
University and measured data, the constitutive equation of aerated concrete recommended in this study was as follows:

$$
y=\left\{\begin{array}{cc}
a x-(1-a) x^{5} & 0 \leq x \leq 1 \\
x /\left[b(x-1)^{2}+x\right] & x>1
\end{array}\right.
$$

The values of undetermined parameters $a$ and $b$ under various water content conditions were shown in Table 3.

Table 3. Parameter $a$ and $b$.

\begin{tabular}{cllllllll}
\hline$\omega$ & $\mathbf{0 \%}$ & $\mathbf{5 \%}$ & $\mathbf{1 0 \%}$ & $\mathbf{2 0 \%}$ & $\mathbf{3 0 \%}$ & $\mathbf{4 0 \%}$ & $\mathbf{5 0 \%}$ & $\mathbf{6 0 \%}$ \\
\hline $\mathrm{a}$ & 1.14 & 1.12 & 1.10 & 1.08 & 1.06 & 1.04 & 1.03 & 1.02 \\
$\mathrm{~b}$ & 1.47 & 1.00 & 1.05 & 1.06 & 0.95 & 1.94 & 1.89 & 0.79 \\
\hline
\end{tabular}

As can be seen from Table 3, with the increased of water content, the a value decreased continuously, indicating that the elastic modulus of AAC decreases. If $\omega \%=60 \%$ and $\omega \%=5 \%$ are taken as examples, the full curve obtained by formula (4) is compared with the measured full curve (As shown in Figure 7). After comparison, it is found that the curve fitting of the rising section is good, the fitting coefficient is above 0.98 , while the fitting curve of the falling section is quite different. These differences may be due to the insufficient rigidity of the testing machine, the testing machine itself deforms during the loading process and stores a large amount of elastic strain energy. when the bearing capacity of the test piece suddenly drops, the testing machine recovers deformation due to the reduction of stress, releases energy immediately, and the test piece is rapidly crushed, resulting in ineffective measurement of the falling section.

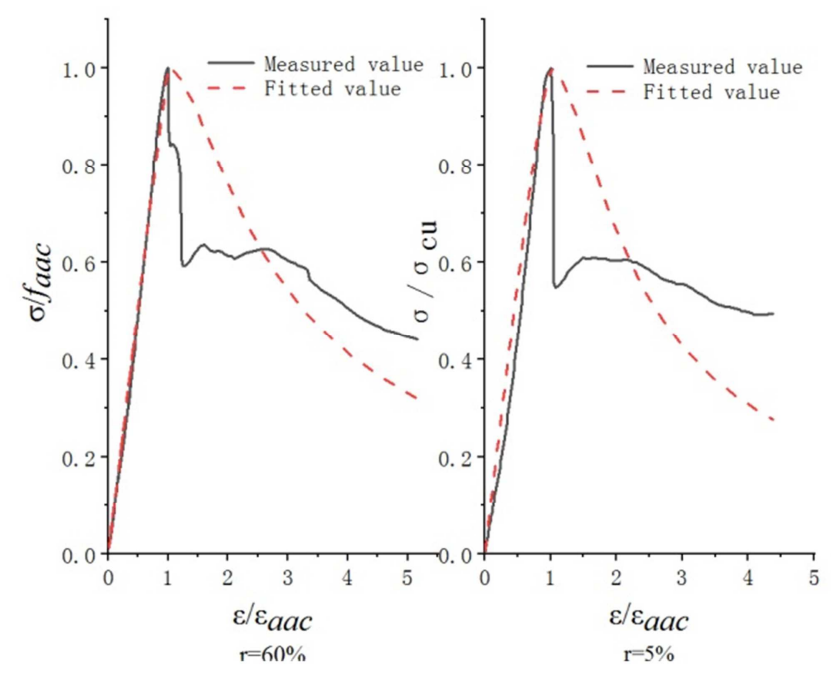

Figure 7. Comparison of test and fitted stress-strain curve.

\section{Conclusion}

In this paper, some basic mechanical properties of AAC were explored experimentally. The constitutive relationship between stress and strain was also discussed. Based on the test resulst, the following conclusions can be drawn:

(1) The moisture content played a significant effect on the failure mode of AAC. Micro-cracks are first generated from the bottom or top of the specimen. When the moisture content of AAC is less than $10 \%$, brittle failure existed and accompanied by a large splitting noise. When the specimen was damaged, it presented obvious vertical cracks in the middle and presents splitting failure mode. When the water content of AAC was larger than $10 \%$, its failure mode was "splayed" or corner failure.

(2) Water content showed a significant impact on the elastic modulus, peak stress and peak strain of AAC. With the increase of water content, AAC's relative resistance to deformation and damage decreased, and the effect of water content on the mechanical properties of AAC was mainly concentrated in the range of $10 \%$. When the water content exceeded $10 \%$, the change of mechanical properties tended to be stable.

(3) The equations of AAC moisture content and its peak stress, peak strain, elastic modulus and constitutive relation under different moisture content conditions were established, which have important reference for in-depth study and exploration of AAC mechanical properties and durability, and can also provide reference for revision and improvement of corresponding specifications and procedures.

\section{Acknowledgements}

This research was National Key R\&D Program of China, supported by Ministry of Science and Technology of the People's Republic Republic of China (No.2016YFC070080101).

\section{References}

[1] Ji-Kuiab M, Jiaa T. Application of Aerated Concrete Selfinsulation System in Cold Region [J]. Building Energy Efficiency, 2015.

[2] Yaoqing X, Qianfeng Y. Experimental study on the total stress-strain curve of porous lightweight concrete [J]. Sichuan Building Science, 2010.

[3] TANG L. Experimental study on effect of moisture content on the performance of the autoclaved aerated concrete block [D]. Hunan University of Science and Technology, 2011. (in Chinese)

[4] Huan Z. Autoclaved Fly Ash-sand Aerated Concrete Stressstrain Full Curve and the Mechanical Properties of the Block Masonry Experiment Research [D]. Changsha University of Technology, 2013. (in Chinese)

[5] Guowei Z, Boshan C, Qisong M, et al. STUDY OF JOINTS OF AUTOCLAVED AERATED CONCRETE SLABS [J]. Industrial Construction, 2017.

[6] Ferretti D, Michelini E, Rosati G. Mechanical characterization of autoclaved aerated concrete masonry subjected to in-plane loading: Experimental investigation and FE modeling $[\mathrm{J}]$. Construction and Building Materials, 2015, 98: 353-365. 
[7] Bonakdar A, Babbitt F, Mobasher B. Physical and Mechanical Characterization of Fiber-Reinforced Aerated Concrete (FRAC) [J]. Cement and Concrete Composites, 2013, 38.

[8] Changtao Y, Shan S, Yang S, et al. Study on rapid estimation of autoclaved aerated concrete compressive strength [J]. New Building Materials, 2017, 44 (07): 52-55.

[9] Zbyek Pavlík, Luká Fiala, Robert erny. Analysis of dielectric mixing models for the moisture assessment of porous building materials [J]. Pollack Periodica. 2009, Vol. 4 (No.2): 79-88.

[10] R Drochytka, J Zach, J Hroudová. Non-destructive Testing of Influence of Moisture on Properties of Autoclaved Aerated Concrete $[\mathrm{J}]$.

[11] Dian-Zhong L, Fa-Yu W, Shu-Ming H E. EXPERIMENTAL RESEARCH FOR CONSTITUTIVE RELATION OF FOAM CONCRETE UNDER UNIAXIAL COMPRESSIONS [J]. Architecture Technology, 2016.

[12] Meng H R, Yao Q F, Zhang Y. Stady on the constitutive model of the lightweight infilled material in multi-ribbed wall structure [J]. Concrete, 2007.

[13] Sun H, Lieping Y E, Ding J, et al. Shrinkage and creep of high-strength lightweight aggregate concrete [J]. Journal of Tsinghua University, 2007.

[14] Wang Z. Experimental study on Mohr-Coulomb model with damage for concrete $[\mathrm{J}]$. Beijing Jiaotong Daxue Xuebao/Journal of Beijing Jiaotong University, 2013, 37 (4): 84-88.

[15] Hanmin L, Feng G. Relation between strength and moisture content of aerocrete [J]. Housing Materials \& Applications, 2004.

[16] Han B, Wang W, Wang Y. Water content effects on compression strength of brick masonry members [J]. Journal of Beijing Jiaotong University, 2011, 35 (1): 6-8.

[17] Guo Z. Chapter 2 - Basic Mechanical Behavior [J]. Principles of Reinforced Concrete, 2014: 9-52. 